\title{
Sistema de transporte rodoviário de cargas: uma proposta para sua estrutura e elementos
}

\author{
Thaís Maria de Andrade Villela ${ }^{1}$ e Giovanna Megumi Ishida Tedesco ${ }^{2}$
}

\begin{abstract}
Resumo: No processo de planejamento de transportes, o entendimento do seu sistema e o conhecimento de cada elemento é fundamental para o sucesso do trabalho. Para direcionar as ações do planejamento de transportes, é imprescindível definir e identificar como se relacionam os elementos dos sistemas. Apesar de sua evidente importância na economia brasileira, nos estudos encontrados sobre o Transporte Rodoviário de Cargas (TRC) é comum a abordagem com foco específico em determinados elementos, mas há uma carência de estudos sobre como os elementos estão relacionados. Assim, este trabalho apresenta uma proposta para a organização dos elementos de um sistema, considerando as relações entre eles. O objetivo é propor as relações que devem ser estabelecidas, de maneira que seja possível definir cada elemento, estabelecer uma hierarquia e organizar as características destes que devem ser consideradas no planejamento. Como aplicação da proposta, foi estruturada uma rede contendo os elementos principais do Sistema TRC.

Palavras-chave: transporte rodoviário, sistema, elementos.
\end{abstract}

\begin{abstract}
In the process of transportation planning, the understanding of the system and knowledge of each element is essential. To direct the actions of transportation planning it is essential to define the systems' elements and identify how they are related. Despite its obvious importance in the Brazilian economy, the studies on Road Freight Transportation (TRC, in Portuguese) usually have an approach with a specific focus on certain elements, but there is a lack of studies on how the elements are related. Therefore, a proposal for organizing the elements of a system, considering the relationships between them is presented in the paper. The goal is to propose that the relationship should be established so that it is possible to define each element, establish a hierarchy and organize the characteristics to be considered in planning. As an application of the proposal a network containing the main elements of the TRC System is presented.
\end{abstract}

Keywords: road transportation, system, elements.

\section{INTRODUÇÃO}

O aparecimento de novas tecnologias de informação propiciou uma maior disseminação das informações, facilitando o acesso dos pesquisadores ao conhecimento. No entanto, as informações muitas vezes encontram-se desorganizadas, trazendo abordagens distintas a respeito de um mesmo objeto. Em se tratando do Sistema de Transporte Rodoviário de Cargas (STRC), além da carência de publicações que abordem sua estrutura, é comum encontrar nomes, definições e enfoques distintos para um mesmo elemento do sistema.

O STRC é um sistema complexo, composto de muitos elementos que se relacionam. Os autores que escrevem a respeito desse sistema não apresentam consenso em relação à sua composição e em relação às características de seus componentes. Alguns elementos estão presentes nas descrições da maioria dos trabalhos, como, por exemplo, as vias e os veículos. No entanto, outros elementos nem sempre são mencionados, como, por exemplo, as cargas transportadas pelo sistema.

Essa percepção reforça a necessidade de organizar os elementos do STRC e identificar as relações que eles estabelecem entre si. Para isso, o presente trabalho discute algu-

\footnotetext{
${ }^{1}$ Thaís Maria de Andrade Villela, Programa de Pós-Graduação em Transportes, Universidade de Brasília, Brasília, DF, Brasil. (e-mail: tmavillela@yahoo.com.br).

${ }^{2}$ Giovanna Megumi Ishida Tedesco, Programa de Pós-Graduação em Transportes, Universidade de Brasília, Brasília, DF, Brasil. (e-mail: g.tedesco@yahoo.com.br).

Manuscrito recebido em 25/5/2011 e aprovado para publicação em 14/6/2011. Este artigo é parte de TRANSPORTES v.19, n.2, 2011. ISSN 2237-1346 (online).
}

mas maneiras de organizar elementos, estruturando o conhecimento a respeito de sistemas de transporte. Na sequência, será apresentada uma proposta de relações entre elementos de um sistema. Por fim, será apresentada uma aplicação considerando os elementos do STRC. Cabe ressaltar que a estrutura do STRC apresentada foi desenvolvida com o objetivo de validar as relações propostas (que podem ser utilizadas na definição de seus elementos), estruturando uma das formas de representação do conhecimento acerca do STRC.

\section{REPRESENTAÇÃO DO CONHECIMENTO}

Considerando as formas de representação do conhecimento, McGarry (apud Furgeri, 2006) afirma que a informação deve ter algum meio que a represente, a fim de que uma pessoa que venha a receber tal informação possa compreendê-la. O autor faz a distinção de quatro tipos de meios que podem ser utilizados para representar uma informação:

i) Sinais: que estabelecem relações com as ações a serem desenvolvidas pelo receptor;

ii) Signos: que indicam a presença física de algo ou algum evento relacionado a ele;

iii) Símbolos: que se constituem de representações culturalmente construídas e reconhecidas por uma comunidade científica; e

iv) Linguagem: elemento fundamental da comunicação humana.

Entretanto, mesmo fazendo uso destes meios, é difícil representar a informação de maneira adequada, pois é sabido que a própria representação é por si só um processo re- 
dutor da informação realizada por um intermediário (Furgeri, 2006). Com foco no campo da informática, Sowa (1999) afirma que, para que a representação do conhecimento atinja seus objetivos, devem ser aplicadas teorias e técnicas de três áreas distintas: a lógica, para se ter uma estrutura formal e regras de inferência; a ontologia, para se terem definidos os termos e símbolos a serem utilizados; e, por fim, a computação, para se conseguir apoio às aplicações que farão uso de tal representação.

\subsection{Ontologia}

O termo ontologia é originário da filosofia e se constitui em um ramo que lida com a natureza e a organização do ser. Quando aplicado por comunidades de Inteligência Artificial e Gestão do Conhecimento, refere-se a conceitos e termos que podem ser usados para descrever alguma área do conhecimento ou construir uma representação deste (Maedech apud Guimarães, 2002). Rios (2005) ressalta que não se deve estabelecer uma relação de sinonímia entre ontologia e base de conhecimento. Em uma definição informal, Sowa e Dietz (apud Rios, 2005) consideram a ontologia como um componente de uma coleção de informações, sendo ela o alicerce para a construção do conhecimento.

Para se realizar o processo de representação do conhecimento, Corradi et al. (2001) afirmam que existem várias formas, tais como: esquemas, redes semânticas, mapas mentais, analogias e redes hipertextuais de significados, entre outras. Estas formas diferem entre si pela natureza dos resultados e pelos meios empregados em sua produção.

\subsection{Redes semânticas}

Corradi et al. (2001) afirmam que as redes semânticas constituem uma das formas de representar o conhecimento acerca de determinado objeto. O conceito para rede semântica foi desenvolvido por Quillian (1968) e representou a primeira tentativa de fornecer uma representação do conhecimento baseado no significado das palavras. Em seu modelo precursor "Semantic Memory", Quillian (1968) tentava representar a semântica das palavras em Inglês. Para isso, ele buscou estruturar um modelo de como o significado das palavras eram representados na memória humana. Quillian (1968) construiu uma rede com nós e links que representavam relações entre as palavras e seus conceitos. Este autor propôs um modelo de representação, chamado de hierarquia semântica ou taxonomia, que utiliza links de dois tipos: (i) que representam relações hierárquicas ou categóricas entre os conceitos; e (ii) que representam características específicas do objeto, associadas a conceitos particulares. Ambos os tipos de ligações são direcionais.

Em seu livro Estrutura Semântica, Baldinger (1970), partindo da constatação da existência de uma clara estruturação dos significantes na língua, procura fazer apontamentos a respeito da configuração desta estrutura. Segundo este autor, existem partes pertencentes a uma mesma classe e que podem ser dispostos de maneira horizontal. Outros, por sua vez, relacionam-se hierarquicamente, podendo ser dispostos de maneira vertical.

$\mathrm{Na}$ língua portuguesa, essas relações definem a maneira pela qual o predicado se liga ao sujeito, e organiza a realidade, facilitando sua compreensão. Desta forma, a estrutura semântica é aquela que, organizada na forma de categorias, permite a visualização de diferentes classes do ser ou as diferentes classes de características que se podem afirmar de um sujeito (objeto de estudo).

Seguindo esse conceito, a ideia de construção semântica resulta na organização de elementos representativos, compondo estruturas, nas quais diferentes elementos podem ser classificados hierarquicamente. Os arcos, que interligam esses elementos, representam a relação existente entre eles e que facilitam sua compreensão (Ceftru, 2008). A principal vantagem das redes semânticas é justamente a possibilidade delas explicitarem as relações entre os elementos. Dessa forma, a estrutura adquire significado (semântica), e permite a decomposição de seus elementos em diferentes classes, ou em diferentes características que podem ser atribuídas ao elemento estudado (Tedesco, 2008).

Para Furgeri (2006), as relações entre os elementos podem ser realizadas a partir de uma categorização (esses elementos são agrupados pela sua natureza), por uma hierarquização (é estabelecida uma ordem de dependência entre os elementos), por uma relação partitiva (um elemento é composto de partes) e por relações de equivalência.

Guarino (1998) divide as relações em estruturantes - aquelas que contribuem para a estruturação do domínio, e não estruturantes - aquelas que fornecem informação adicional a objetos já identificados. Smith et al. (apud Gonçalves e Souza, 2008) enfatizam a dificuldade em enumerar todas as relações possíveis e argumentam que algumas relações são primitivas e independentes de domínio. São três as relações binárias listadas por esses autores: relação classeclasse, relação instância-classe e relação instânciainstância.

Entende-se que as redes semânticas podem representar diferentes conceitos, explicitando diferentes relações entre os elementos. Sowa (1992) classifica as redes semânticas em seis tipos mais comuns:

i) Redes de definição - é o tipo mais antigo das redes semânticas. Apresenta a relação "é um" como principal, suportando regras de herança por meio da passagem das propriedades de um tipo superior para todos os tipos inferiores a ele;

ii) Redes de asserção - são estruturadas a fim de garantir proposições lógicas. Diferente das redes de definição, a informação em uma rede assertiva é assumida como contingentemente verdadeira, a menos que seja explicitamente marcada por um operador modal;

iii) Redes de implicação - a implicação é a principal relação utilizada, sendo a lógica e a probabilística as principais abordagens aplicadas a esse tipo de rede;

iv) Redes executáveis - permitem alteração dinâmica da rede por possuírem mecanismos para execução de inferências, passagem de mensagens ou busca por padrões e associações;

v) Redes de aprendizado - constroem ou estendem sua representação por meio da aquisição de conhecimento provindo de exemplos. O novo conhecimento pode alterar a rede antiga adicionando ou apagando nós e arcos ou modificando valores numéricos, chamados pesos, associados aos nós e arcos; e

vi) Redes híbridas - combina duas ou mais das redes 
anteriores em uma única ou em redes separadas, mas com interação.

Para o desenvolvimento da estrutura contendo elementos e características do STRC, o presente trabalho propõe a adoção de uma rede híbrida, contendo três tipos de relações entre os elementos. Esta proposta está detalhada no item 4.

\section{SISTEMA DE TRANSPORTE RODOVIÁRIO DE CARGAS (STRC)}

Apesar de sua evidente importância na matriz de transporte brasileira, as referências bibliográficas encontradas a respeito do Transporte Rodoviário de Cargas nem sempre tratam de forma organizada a estrutura e os elementos do seu sistema ou do Sistema de Transporte de Cargas realizado por outros modos de transporte.

Além da maioria das publicações encontradas abordar o transporte de passageiros, as publicações sobre o transporte de carga tratam o tema com foco na logística das operações ou elementos específicos do sistema, sem relacioná-los uns aos outros. Encontra-se, por exemplo, trabalhos específicos sobre a carga transportada (e.g. Moura e Banzato, 1997 e Rodrigues, 2007), sobre os veículos utilizados (e.g. ABNT, 2006) ou sobre a infraestrutura (vias, terminais etc.). No entanto, a maneira como esses elementos se relacionam para formar uma estrutura única e integrada do STRC ainda não é explorada pela literatura técnica.

\subsection{Elementos dos Sistemas de Transportes}

A palavra "sistema" tem origem grega (systema) e significa reunião, grupo ou conjunto. Para Bertalanffy $(1973,1989)$, a definição geral da palavra sistema corresponde a "certo número de elementos em interação". Bertalanffy foi um dos primeiros autores a estudar os sistemas, tendo desenvolvido a Teoria Geral dos Sistemas, que foi a base utilizada pela maior parte dos estudos desenvolvidos posteriormente. Seus estudos são fundamentados na biologia, a partir dos quais estudou a organização e o funcionamento de sistemas de organismos vivos. Além disso, parte de suas formulações se remete à teoria dos sistemas abertos.

Diversas são as definições e composições encontradas na literatura para os sistemas de transportes especificamente. O que está apresentado aqui não é uma análise exaustiva sobre o assunto, mas um resumo do que foi encontrado nas principais fontes literárias com abordagem de transporte, discutida também por Tedesco (2008) e por Ceftru (2008).

A relação dos componentes que formam um sistema de transporte é variada de acordo com cada autor. Alguns autores se limitam aos aspectos físicos, dando ênfase à infraestrutura, e outros autores complementam com aspectos operacionais. Em relação aos componentes do sistema de transporte, Manhein (1979) cita os seguintes:

- Pessoas e bens transportados;

- Veículos que os transportam; e

- Redes através das quais os veículos se deslocam.

Com uma abordagem bem próxima à definição de Manhein (1979), Febbraro e Sacone (1996) citam que um sistema de transporte consiste de dois principais componentes:

- Sistema de demanda, que representa as necessidades e comportamento dos usuários; e

- Sistema de oferta, que inclui tudo que está relacionado à produção do serviço, desde a infraestrutura até o planejamento de regras do sistema.

Como os fatores demanda e oferta estão relacionados entre si, para Febbraro e Sacone (1996), um modelo de sistema de transportes pode ser considerado como a integração dos modelos de demanda e de oferta e suas interações.

Ainda, Setti e Widmer (1997) citam que os elementos funcionais que permitem a movimentação de pessoas e bens são: veículos; vias; terminais e plano de operação. Distinguindo apenas um desses elementos, Khisty e Lall (1998) seguem uma linha próxima. Ao invés de listarem o "plano de operação" como elemento do sistema de transportes, Khisty e Lall (1998) citam os "técnicos que constroem, operam, gerenciam e mantém as vias, os veículos e os terminais". Para os autores, esses quatro elementos (vias, veículos, terminais e técnicos) interagem com o humano, sendo usuário ou não usuário do sistema, e também com o meio ambiente.

Além destes componentes, certos autores ainda apontam três outros: os dispositivos de unitização de cargas, as interseções e a força de trabalho (Khisty, 1990). Com um maior nível de detalhamento, Morlok (1978) lista os componentes do sistema de transportes como sendo:

- Objeto a ser movido: por exemplo, passageiros e cargas;

- Caminho a ser percorrido;

- Veículo: dá ao objeto mobilidade em determinado tipo de caminho;

- Contêiner: compartimento por onde os objetos podem ser transportados para facilitar a movimentação. A diferença do contêiner para o veículo é que o container sozinho não consegue dar mobilidade ao objeto;

- Custos: do uso da terra, da mão de obra e dos materiais utilizados na manutenção e construção inicial;

- Terminais: qualquer estrutura em um caminho onde os veículos podem parar para serem carregados e descarregados; e

- Plano de Operação: conjunto de procedimentos que regem a operação do sistema.

Em linha semelhante, Meyer e Miller (1984) citam seis principais componentes dos sistemas de transportes que geralmente são relacionados a políticas de transporte de diferentes tipos:

- Veículos que operam na infraestrutura do sistema;

- Rotas que regem a operação dos veículos sobre a infraestrutura;

- Infraestrutura do sistema de transportes, que inclui as vias em que os veículos circulam, os sistemas de sinalização, terminais, e qualquer outra instalação física fixa necessária para operação e manutenção do sistema de transporte;

- Motoristas dos veículos;

- Procedimentos para operação do sistema, que incluem todas as regulamentações do governo (e.g. velocidade máxima permitida, documentação etc.); e 
Tabela 1. Abordagens sobre Sistemas de Transportes

\begin{tabular}{|c|c|c|}
\hline Autor & Definição / Finalidade & Componentes \\
\hline Morlok (1978) & $\begin{array}{l}\text { O sistema de transporte possibilita que um objeto } \\
\text { seja movimentado de um local para outro ao lon- } \\
\text { go de uma trajetória, por meio de uma tecnologia. }\end{array}$ & $\begin{array}{l}\text { Objeto; } \\
\text { Caminho; } \\
\text { Veículo; } \\
\text { Container; } \\
\text { Custos; } \\
\text { Terminais; } \\
\text { Plano de Operação. }\end{array}$ \\
\hline $\begin{array}{l}\text { Wingo e Perloff apud } \\
\text { Bruton (1979) }\end{array}$ & $\begin{array}{l}\text { Conjunto de facilidades e instituições organizado } \\
\text { para distribuir seletivamente uma qualidade de } \\
\text { acesso em uma área urbana }\end{array}$ & \\
\hline Manhein (1979) & $\begin{array}{l}\text { Um sistema de transportes é uma forma particular } \\
\text { de mercado, no qual a oferta e a demanda atingem } \\
\text { o equilíbrio considerados os canais restritivos da } \\
\text { malha de transportes. }\end{array}$ & $\begin{array}{l}\text { Pessoas e bens transportados; } \\
\text { Veículos que os transportam; } \\
\text { Redes através das quais os veículos se deslo- } \\
\text { cam. }\end{array}$ \\
\hline Meyer e Miller (1984) & & $\begin{array}{l}\text { Infraestrutura; } \\
\text { Veículos; } \\
\text { Rotas; } \\
\text { Motoristas; } \\
\text { Procedimentos para operação do sistema; } \\
\text { Custos. }\end{array}$ \\
\hline Febbraro e Sacone (1996) & $\begin{array}{l}\text { Integração dos modelos de demanda e de oferta e } \\
\text { suas interações. }\end{array}$ & $\begin{array}{l}\text { Sistema de demanda; } \\
\text { Sistema de oferta (supply), }\end{array}$ \\
\hline Setti e Widmer (1997) & $\begin{array}{l}\text { Conjunto de elementos que têm como função } \\
\text { permitir que pessoas e bens se movimentem. }\end{array}$ & $\begin{array}{l}\text { Veículos; } \\
\text { Vias; } \\
\text { Terminais; } \\
\text { Plano de operação. }\end{array}$ \\
\hline Khisty e Lall (1998) & & $\begin{array}{l}\text { Vias; } \\
\text { Veículos; } \\
\text { Terminais; } \\
\text { Técnicos que constroem, operam, gerenciam e } \\
\text { mantém as vias, os veículos e os terminais. }\end{array}$ \\
\hline
\end{tabular}

Tabela 2. Quantidade de registros, segundo a categoria do transportador

\begin{tabular}{lcc}
\hline Categoria & Quantidade de transportadores & \% \\
\hline Autônomos & 671.781 & $84,0 \%$ \\
Empresas & 127.595 & $15,9 \%$ \\
Cooperativas & 623 & $0,1 \%$ \\
TOTAL & 799.999 & $100,0 \%$ \\
\hline
\end{tabular}

- Custos dos operadores e/ou usuários do sistema, que não são somente os relacionados à infraestrutura, veículos e procedimentos de operação, mas também os que são diretamente influenciados pela regulamentação e subsídios.

Na Tabela 1 estão apresentadas as definições e componentes dos sistemas de transportes encontradas na literatura e descritas no presente item:

\subsection{Transporte Rodoviário de Cargas}

O transporte rodoviário de cargas (TRC) é aquele realizado em rodovias. O veículo utilizado neste transporte pode ser tanto um veículo unitário (e.g. caminhão simples) quanto uma combinação de veículos de carga (CVC, que é composta por um veículo trator e um - ou mais - veículo rebocável); com compartimentos de carga que são função do tipo de carga a ser transportada.

O TRC é uma atividade que pode ser realizada pelo próprio dono da carga (Transporte de Carga Própria - TCP), ou pode ser feita por um transportador, contratado para realizar este serviço (Transporte Rodoviário Remunerado de Cargas - TRRC).
No Brasil, os transportadores que exercem atividade remunerada de transporte de carga podem ser autônomos, empresas ou cooperativas. Estes transportadores são obrigados por Lei a se cadastrar e obter o Registro Nacional de Transportadores Rodoviários de Cargas (RNTRC).

No RNTRC estão cadastradas as principais características dos transportadores e de sua frota. Os transportadores distribuem-se nessas três categorias na seguinte proporção (Tabela 2):

A economia brasileira ainda é bastante dependente do modo rodoviário, fato que pode ser observado pela atual Matriz de Transporte brasileira, em que esse modo representa mais de $60 \%$ do total de cargas transportadas (movimentando cerca de 485,6 bilhões de toneladas-quilômetro útil - TKU). Dados da Associação Nacional do Transporte de Cargas e Logística (NTC) indicam que o TRC responde por 3,4\% do PIB nacional, e gera 3,5 milhões de empregos (Cruz, 2008).

Sendo assim, evidencia-se a importância dos estudos a respeito do STRC e a identificação de seus componentes para um planejamento do setor de maneira mais eficiente e eficaz. 


\section{PROPOSTA DE ESTRUTURA DOS ELEMENTOS DO STRC}

A criação de um padrão para a estruturação de objetos e conceitos mostra-se cada vez mais necessária, visto que objetiva melhorar a representação do conhecimento e, conseqüentemente, melhorar a recuperação de informações e agilizar o processo de transmissão destas (Furgeri, 2006).

Este trabalho propõe o uso de redes híbridas, com adoção de três relações distintas entre seus elementos, de maneira que seja possível defini-los, estabelecer sua hierarquia e estabelecer as características destes que devem ser consideradas no planejamento. Para validação do trabalho, uma aplicação da proposta permitiu a estruturação de uma rede contendo os elementos principais do STRC.

\subsection{Procedimento geral para construção da estrutura de organização}

Tedesco et al. (2009) apresentam uma metodologia para a construção e a disseminação do conhecimento sobre o STRC por meio da realização de oficinas, com a participação de especialistas do setor. Segundo os autores, as oficinas propiciam um debate entre os participantes e são fundamentais para a construção e disseminação do conhecimento, visto que cada especialista possui conhecimento aprofundado sobre determinado elemento isoladamente, mas que nem sempre domina com clareza os demais elementos e suas relações. Naquele trabalho foram apresentados também os resultados da primeira aplicação da metodologia, que consistiu em uma oficina acerca da infraestrutura viária e da sinalização utilizadas pelo TRC.

O presente estudo é uma complementação da proposta de Tedesco et al. (2009), uma vez que apresenta uma base para realização da primeira etapa da metodologia proposta por aqueles autores. A primeira etapa da metodologia proposta por Tedesco et al. (2009) consiste na "pré-estruturação" das oficinas. Nesta etapa, segundo os autores, devem ser realizados:

- Pesquisa bibliográfica - levantamento bibliográfico de referências acerca dos elementos componentes do sistema;

- Construção da estrutura inicial do sistema - após a revisão bibliográfica mais aprofundada referente a cada elemento, deve-se detalhar sua estrutura, considerando sua composição e suas características;

- Análise da estrutura do sistema com a equipe - rea- lização de validações e apresentação de uma estrutura inicial desenvolvida; $\mathrm{e}$

- Validação da estrutura do sistema - validação da estrutura inicial pelo responsável pela pesquisa.

A forma de organização dos elementos, baseada em redes híbridas, para construção da estrutura inicial do STRC é uma maneira de orientar a pré-estruturação da oficina, mas também deve estar presente em todas as demais etapas da metodologia proposta por Tedesco et al. (2009), principalmente nas atividades de discussão sobre o objeto de estudo.

É importante ressaltar que, para validação da estrutura final do STRC, recomenda-se seguir as demais etapas da metodologia proposta por Tedesco et al. (2009). A aplicação de todas as etapas propostas por aqueles autores não é objeto do presente trabalho. No entanto, para validar os procedimentos propostos, a metodologia proposta pelos autores foi aplicada ao STRC, desenvolvendo-se, assim, o detalhamento de um dos elementos do STRC.

\subsection{Estrutura de organização: relações entre elementos}

Devido à complexidade dos elementos de um sistema de transporte, mostra-se mais indicada a estruturação de redes híbridas, em que são utilizadas mais de uma forma de relação entre elementos pertencentes a diferentes hierarquias. A seguir são propostas três diferentes relações entre os elementos da rede: composição, caracterização e tipos.

\subsubsection{Relação de composição: "é composto por"}

A título de exemplificação, considera-se como objeto de estudo uma cadeira. Basicamente observa-se que ela é formada por quatro partes: assento, pernas, braços e encosto (Figura 1).

A relação entre o primeiro elemento (1) e os demais é uma relação de composição, ou seja: a cadeira é composta por pernas, braços, encosto e assento. Fazendo-se a leitura da relação no sentido inverso: pernas, braços, encosto e assento são componentes de uma cadeira.

\subsubsection{Relação de caracterização: "é caracterizada por"}

Cada elemento também pode apresentar características. Seguindo com o exemplo da cadeira, pode-se dizer que o elemento "assento" apresenta algumas características (Figura 2):

A relação entre o elemento "assento" (1.4) e os demais é

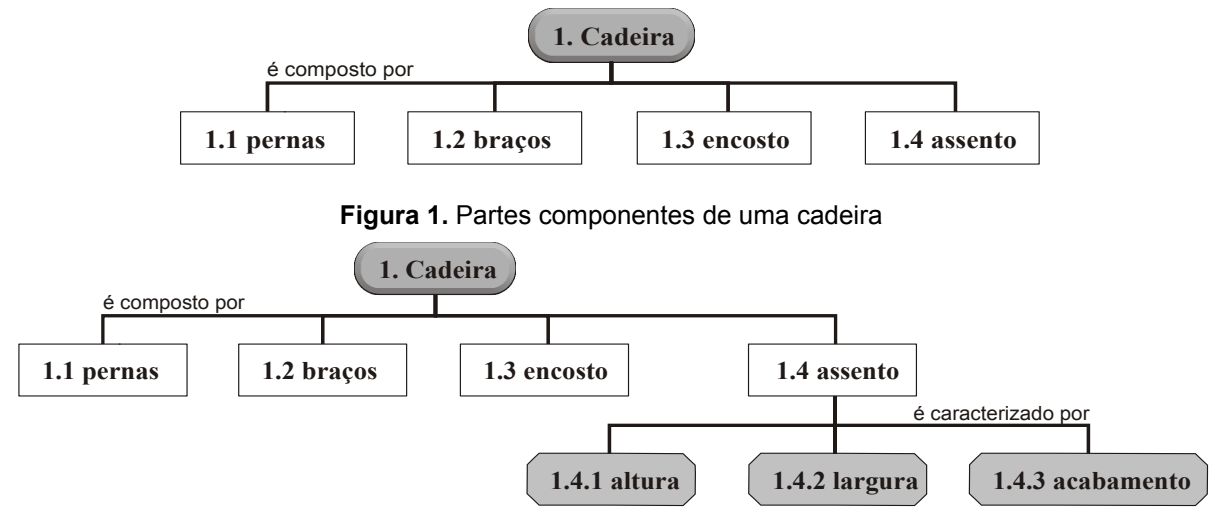

Figura 2. Características do assento 


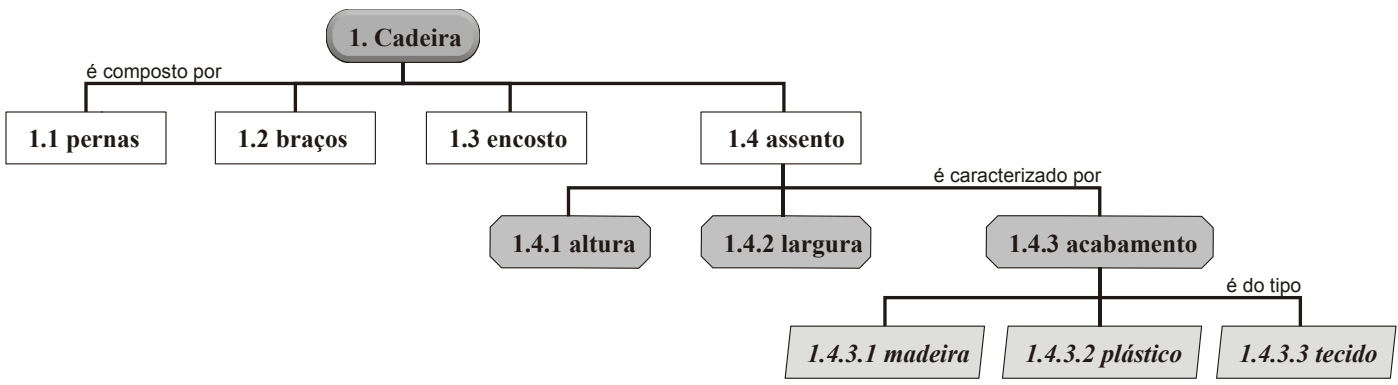

Figura 3. Tipos de acabamento do assento

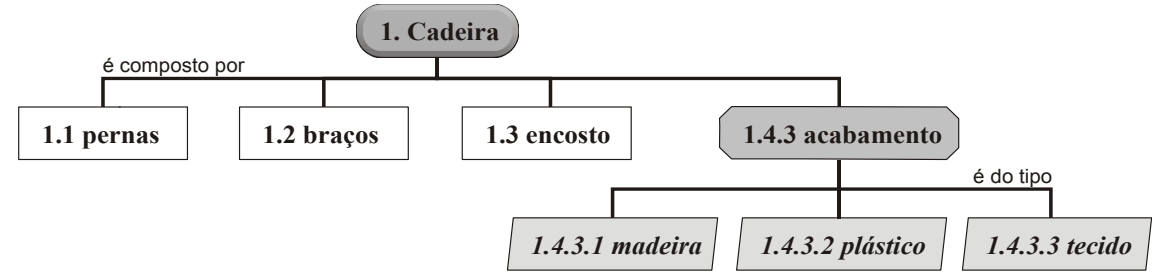

Figura 4. Ilustração de relações distintas em um mesmo nível (não recomendável)

uma relação de caracterização. Dessa maneira, pode-se dizer que o assento caracteriza-se por sua altura, largura e por seu tipo de acabamento. Fazendo a leitura das relações de uma estrutura no sentido inverso, diz-se que altura, largura e acabamento são características de um assento.

\subsubsection{Relação por tipos: "é do tipo"}

Um determinado componente ou uma determinada característica pode apresentar diferentes tipos. Por exemplo: o acabamento do assento (1.4.3) pode ser de distintos tipos (Figura 3).

A relação entre o elemento "acabamento" (1.4.3) e os demais é de tipo. Assim, pode-se dizer que o acabamento pode ser dos tipos madeira, plástico ou tecido. Ao proceder a leitura inversa, diz-se que madeira, plástico e tecido são distintos tipos de acabamento do assento de uma cadeira.

É importante salientar que elementos de uma mesma hierarquia devem seguir o mesmo padrão de relação. Ou seja, não se pode misturar uma característica com um componente, ou um tipo com uma característica (Figura 4). Pernas, braços e encosto são componentes, enquanto o acabamento é uma característica. Portanto, as relações entre este último elemento e o elemento acima dele (característica) seria diferente da relação entre os demais e o mesmo superior (composição).

\subsection{Estrutura organizada do sistema de transporte rodoviário de cargas}

Como aplicação da proposta feita no capítulo anterior, desenvolveu-se uma pesquisa sobre os elementos componentes do STRC. A organização da estrutura inicial do STRC deu-se a partir de pesquisas sobre o setor de transporte rodoviário de cargas no Brasil, por meio de revisão bibliográfica, pesquisa documental e reuniões com especialistas do setor - seguindo a metodologia proposta por Tedesco et al. (2009). Sendo assim, foram definidos os principais elementos do STRC:

- Infraestrutura - aspectos da rede viária utilizada para o TRC, características físicas e operacionais das vias e terminais existentes;

- Veículos - principais características dos veículos utilizados para o transporte de cargas, bem como dos equipamentos utilizados para a movimentação das cargas (embarque, desembarque, embalagem etc.);

- Carga - principais características das cargas movimentadas no transporte rodoviário; e

- Atores - principais atores (stakeholders) e entidades envolvidas com o TRC.

Seguindo a lógica da rede híbrida construída com base em três relações distintas entre os elementos, para cada um dos elementos do STRC foram identificadas as relações que eles estabelecem entre si. É importante ressaltar que quanto mais vezes determinado elemento é "decomposto", mais completa (e também complexa) fica a representação do sistema.

No primeiro nível, identificou-se uma relação de composição dos elementos "infraestrutura", "veículo", "carga" e "atores" com o STRC, ou seja, conforme esta proposta inicial de estrutura do STRC, o sistema é composto por esses quatro elementos.

Em um segundo nível, identificou-se que a "infraestrutura" é composta pela rede viária, pelos terminais e pelos pontos de apoio. Há uma relação de composição entre os elementos, ou seja, a rede viária, os terminais e os pontos de apoio compõem a infraestrutura do STRC. Para dar continuidade neste processo, o mesmo tipo de decomposição pode ser feito para cada um destes elementos citados e assim por diante.

Já o elemento "veículos" tem como características sua composição física, configuração (caminhão plataforma ou CVC, por exemplo), geometria, peso, classificação, configuração dos eixos, área em que trafega, tecnologias utilizadas, tipo de propriedade e ano de fabricação. Todos os elementos listados são categorias de características dos veículos, ou seja, há uma relação de caracterização entre os elementos listados e os "veículos". Os veículos são "categorizados" por estes elementos. 


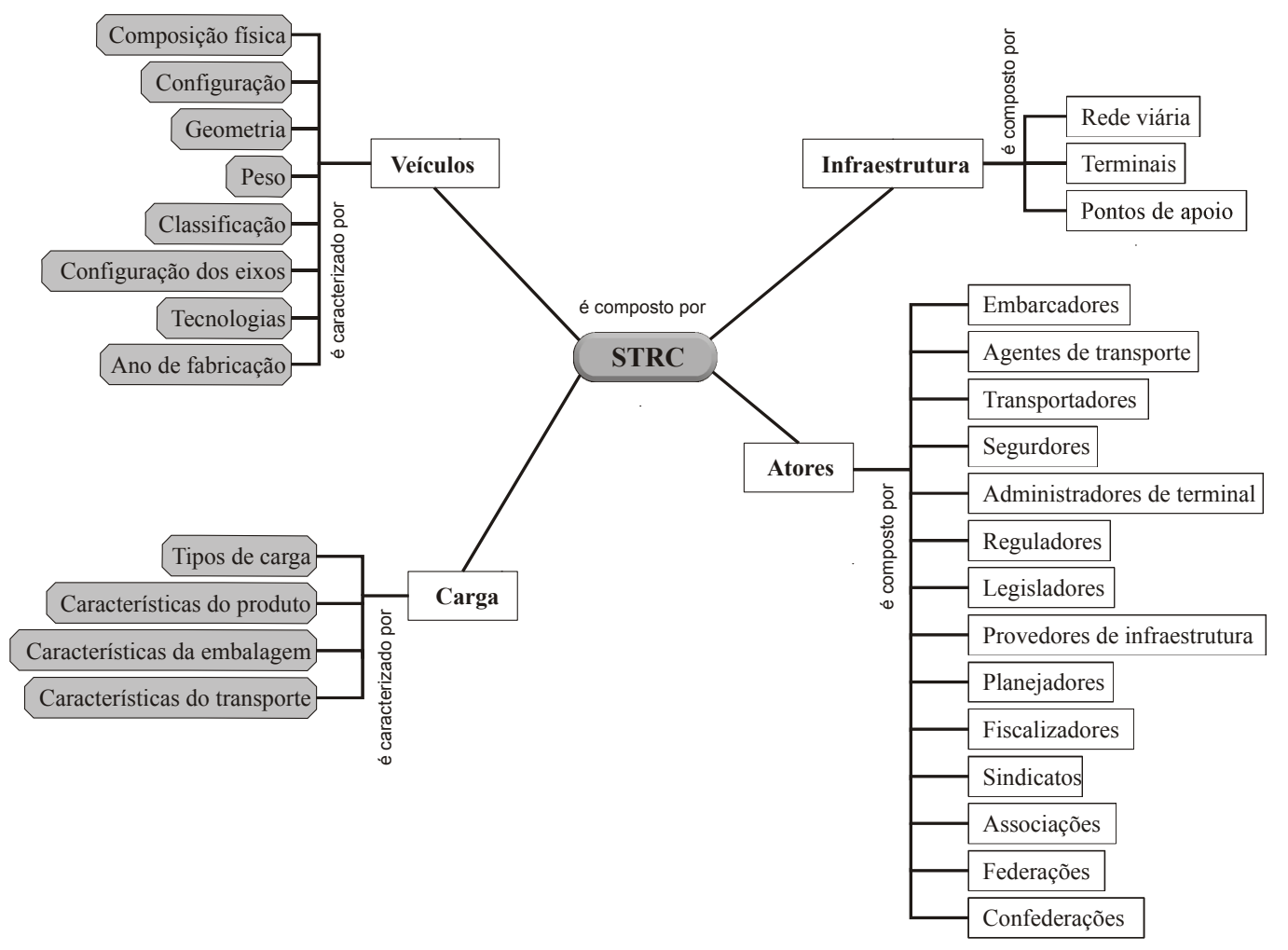

Figura 5. Principais elementos do STRC e suas relações

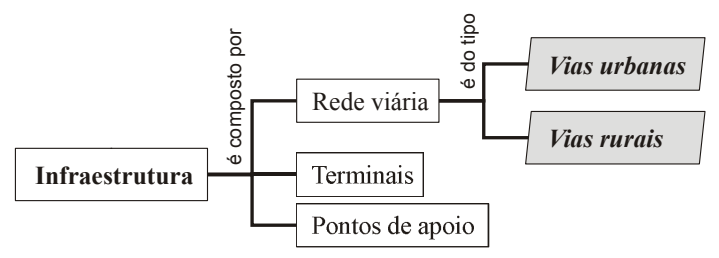

Figura 6. Detalhamento de "Rede viária"

As "cargas" podem ser decompostas pelo seu tipo (geral, granel etc.), pelas características do produto (volume, peso etc.), pelas características das embalagens e também pelas características de transporte que demandam. A relação identificada neste caso também foi de caracterização, uma vez que estes elementos caracterizam as cargas a serem transportadas.

Por fim, foram identificados alguns "atores" por "tipo", ou seja, foram discriminados diversos "grupos" envolvidos com o TRC. Alguns deles são: transportadores, embarcadores, seguradores, planejadores, fiscalizadores, sindicatos, associações, entre outros. Esta lista pode ser extensa, mas é importante identificar os principais grupos, ou os principais “tipos”, de atores. Neste nível, ainda não é recomendável que se identifiquem os "nomes" (quais são as empresas ou quais são as entidades). A identificação inicial dos "grupos por sua função" é mais útil para a construção do conhecimento a respeito do tema e para o planejamento do setor. $\mathrm{Na}$ Figura 5, estão representados os principais elementos do STRC citados e as relações entre eles.

A metodologia proposta por Tedesco et al. (2009) foi aplicada em um dos elementos do segundo nível de "Infraestrutura". Em oficina realizada com técnicos e especialistas em transportes, detalhou-se a estrutura do elemento "Rede viária".

No terceiro nível, os elementos apresentam relação de tipo. Vias urbanas e vias rurais são tipos de vias da Rede viária (Figura 6).

No quarto nível os elementos representam relações de caracterização. Os participantes da oficina definiram que as vias urbanas apresentam como características: classe funcional, jurisdição, diretrizes de traçado, elementos construtivos e sinalização (Figura 7).

As "Classes funcionais". "Jurisdição" e "Sinalização" são divididas em elementos cuja relação é de "tipos". Assim, as vias urbanas, quanto à classe funcional, podem ser do tipo: Arterial, coletora ou local. Quanto à Jurisdição, as vias podem ser do tipo: Federal, Estadual ou Municipal. Por fim, a sinalização pode ser do tipo vertical ou horizontal.

Já os "Elementos construtivos" são subdivididos em elementos cuja relação é de composição. Assim, o conjunto de elementos construtivos é composto por: segmentos viários, intersecções e cruzamentos, pavimento, drenagem, obras de arte e elementos de segurança.

Como ressaltam Tedesco et al. (2009), por se tratar da fase inicial de uma estruturação do conhecimento sobre o STRC, o acesso à oficina que discutiu a rede viária foi res- 


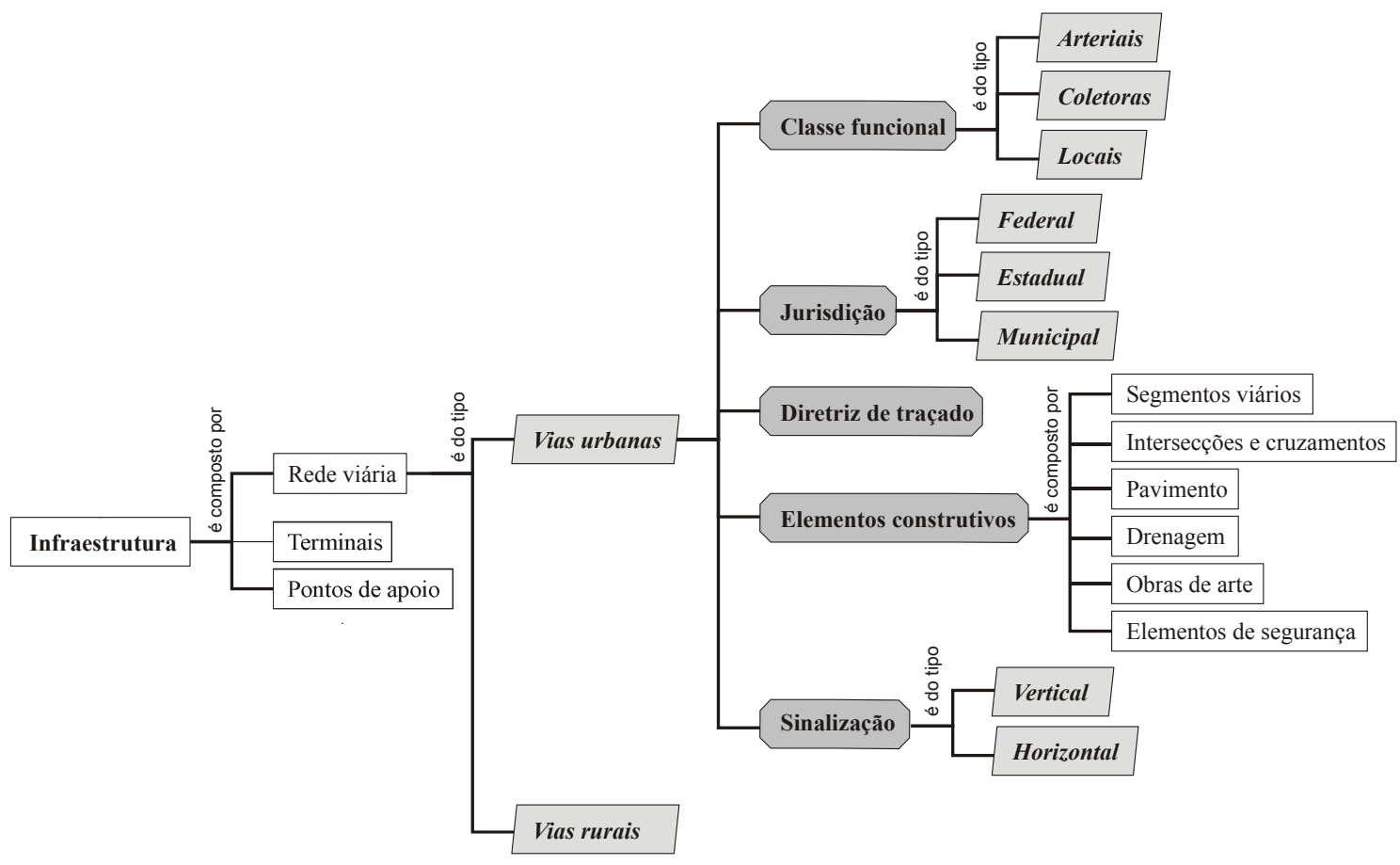

Figura 7. Detalhamento de "Vias urbanas"

trito apenas a alguns representantes de entidades específicas, pois os procedimentos ainda estavam sendo construídos e testados. No entanto, a partir dos resultados obtidos, é possível afirmar que os procedimentos foram compreendidos e aceitos pelos participantes, permitindo a estruturação de uma rede semântica formada por elementos que representassem os três tipos de relação propostos para a estrutura do STRC.

\section{TÓPICOS CONCLUSIVOS}

Os estudos de transportes apresentam como um fator imprescindível o conhecimento a respeito do sistema de transportes no qual se pretende intervir. Dessa forma, esses estudos apresentam a informação como uma de suas maiores necessidades e principais ferramentas para o ato de planejar. Ainda que pretenda atuar em apenas uma parte restrita do sistema, o planejador deve possuir informações a respeito do seu todo, de sua composição e de como os elementos do sistema estão relacionados. Portanto, esse conhecimento deve estar disponível, de forma organizada, ao planejador e aos demais atores do sistema.

Como as informações muitas vezes encontram-se desorganizadas, com abordagens distintas a respeito de um mesmo objeto, este trabalho propõe uma forma de organizar as informações sobre transportes. Foi proposta a representação do conhecimento por meio de redes híbridas, com a adoção de três tipos de relação: composição, caracterização e tipos. Esse tipo de organização se mostrou eficiente uma vez que permite uma visão geral e estruturada do objeto de estudo. Esta perspectiva é fundamental para organização da grande quantidade de informação existente, permitindo um conhecimento mais conciso sobre o objeto em análise. O exemplo de aplicação no STRC mostrou que a utilização das relações propostas é viável e útil para o conhecimento geral e estruturado do sistema.

Considerando a grande participação do TRC na economia brasileira, pesquisas sobre seu sistema podem trazer grandes benefícios. Elas são essenciais, por exemplo, para subsidiar ações do poder público, permitindo melhor planejamento em investimentos, incentivos aos transportadores e melhorias no planejamento do setor.

\section{AGRADECIMENTOS}

À equipe técnica do projeto "Desenvolvimento de Sistema de Informação para Cadastro e Habilitação do Transportador Rodoviário Remunerado de Carga", desenvolvido no Centro Interdisciplinar de Estudos em Transportes da Universidade de Brasília - Ceftru/UnB e aos participantes da $1^{\mathrm{a}}$ Oficina de Construção e a Disseminação do Conhecimento sobre o STRC.

\section{REFERÊNCIAS BIBLIOGRÁFICAS}

Baldinger, K. (1970) Teoría Semántica: Hacia una semántica moderna. Ediciones Alcalá, Madrid.

Bertalanffy, L. V. (1973) Teoria Geral dos Sistemas. Vozes, Petrópolis.

Bertalanffy, L. V. (1989) Teoria General de Los Sistemas - fundamentos, desarrollo, aplicaciones ( $7^{\mathrm{a}}$ ed.). Tradução: Juan Almela. Fundo de Cultura Económica, México.

ABNT (2006) NBR 9762: Terminologia. Associação Brasileira de Normas Técnicas, Rio de Janeiro.

Bruton, M. (1979) Introdução ao planejamento dos transportes. Tradução: João Bosco Furtado Arruda, Carlos Braune, César Cals de Oliveira Neto. Editora Interciência, Rio de Janeiro; Editora da Universidade de São Paulo, São Paulo.

Ceftru. (2008) Diagnóstico do Transporte Escolar Rural - Apêndice 02: Rede Semântica do Sistema de Transporte Escolar Rural. Centro de Formação em Recursos Humanos de Transportes, UnB, Brasília, DF.

Corradi, F. M.; J. R. C. Souza; L. C. P. Travassos e R. F. Dias (2001) Nós, links, e redes... Revista de Biologia e Ciências da Terra, v. 1, n. 1.

Cruz, E. (2008) Risco de Colapso. Revista CNT - Transporte Atual, n. 158.

Febbraro, A. Di e S. Sacone (1996) Modelling and Performance Analysis of Urban Transportation Networks. In:Bianco, L. e P. Toth (eds.). Advanced Methods in Transportation Analysis. Springer, Berlin. 
Furgeri, S. (2006) Representação de Informação e Conhecimento: Estudo das Diferentes Abordagens entre a Ciência da Informação e a Ciência da Computação. Dissertação (mestrado). Ciência da Informação, Pontifícia Universidade Católica de Campinas. Campinas.

Gonçalves, J. A. e R.R. Souza (2008) Relações e Conceitos em Ontologia: teorias de Farradane e Dahlberg. Seminário de Pesquisa e Ontologia no Brasil, Departamento de Ciência da Informação, Universidade Federal Fluminense, Niterói. Disponível em: <www.uff.br/ ontologia/artigos/15.pdf $>$ (Acesso em 12/10/2011).

Guarino, N. (1998) Formal Ontology and Information Systems. In: Guarino, N. (ed.) Formal Ontology in Information Systems. Proceedings of FOIS'98, Trento; IOS Press, Amsterdam.

Guimarães, F. J. Z. (2002) Utilização de ontologias no domínio B2C. Dissertação (mestrado). Departamento de Informática, Pontifícia Universidade Católica do Rio de Janeiro. Rio de Janeiro.

Khisty, C. J. (1990) Transportation Engineering: An Introduction, Prentice Hall, Englewood Cliffs, NJ, EUA.

Khisty, C. J. e B. K. Lall (1998) Transportation Engineering: an Introduction. Prentice Hall, Englewood Cliffs, NJ, EUA.

Manhein, M. L. (1979) Principles of Transport System Analysis. Highway Research Record, n. 180.

Meyer, M. D. e E. J. Miller (1984) Urban Transportation Planning: A decision-oriented approach. McGraw-Hill, New York, NY, USA.

Morlok, E. K. (1978) Introduction to transportation engineering and planning. McGraw-Hill, Tokyo.

Moura, R. A. e J. M. Banzato (1997) Manual de Logística Volume 3 - Embalagem, Unitização \& Conteinerização. Instituto IMAM, São Paulo.

Quillian, M. R. (1968) Semantic memory. In: Minsky, M. (ed.). Semantic information processing. MIT Press, Cambridge, MA, USA.

Rios, J. A. (2005) Ontologias: alternativa para a representação do conhecimento explícito organizacional. Encontro Nacional de Ciência da Informação, VI CINFORM, Salvador.

Rodrigues, P. R. A. (2007) Gestão Estratégica da Armazenagem (2a ed.). Aduaneiras, São Paulo.

Setti, J. R. e J. A. Widmer (1997). Tecnologia de transportes. Notas de Aula, xerografado. USP, São Carlos.

Sowa, J. F. (1992). Semantic Networks. Versão revisada e estendida do artigo original. In: Shapiro, S. C. (ed.) Encyclopedia of Artificial Intelligence (1987). Disponível em: <www.jfsowa.com/pubs/ semnet.htm> (Acesso em 06/10/2008).

Sowa, J. F. (1999) Knowledge Representation: Logical, Philosophical, and Computational Foundations. Disponível em: <www.jfsowa.com/ krbook/krpref.htm $>$ (Acesso em 09/10/2008).

Tedesco, G. M. I. (2008). Metodologia para Elaboração do Diagnóstico de um Sistema de Transporte. Dissertação (mestrado). Programa de Pós-Graduação em Transportes, Universidade de Brasília. Brasília.

Tedesco, G. M. I.; T. M. A. Villela; P. C. V. Cibulska e S. R. Granemann (2009) Procedimentos para a construção da estrutura do sistema de transporte rodoviário de cargas. In: Anais do Congresso de Pesquisa e Ensino em Transportes, XXIII ANPET. Vitória, v.1. 